\title{
Realities and challenges for female cardiothoracic surgeons: an African perspective
}

\author{
Susanna M. Vosloo \\ Cardiothoracic Surgeon, Christiaan Barnard Memorial Hospital, Cape Town, Western Cape, South Africa \\ Correspondence to: Susan M. Vosloo, MBChB, FCS(SA), MMed (UCT). Suite 1401, Christiaan Barnard Memorial Hospital, DF Malan Street, \\ Foreshore, Cape Town, 8001, Western Cape, South Africa. Email: susanvosloo@icloud.com.
}

\begin{abstract}
It is a fact that, despite the worldwide increasing intake of women in medical schools, women are still grossly underrepresented in all medical and surgical specialities, and definitely in cardiothoracic surgery in both developed and developing countries. This is counter-productive towards meeting the escalating need for cardiac surgical care in Africa. However, the natural evolution over time of increasing numbers of females entering medical school and specializing in the field of surgery, is expected to continue despite multiple challenges encountered on their way. The inequities of healthcare provision in Africa in particular needs the continual support of all professionals that are able to contribute to the wellbeing of those innocent individuals that need medical care particularly children born with congenital cardiac defects. In addition to factors on the African continent, realities and challenges for future female cardiothoracic surgeons include gender bias and gender-based discrimination by some male counterparts. The question must be asked: "Is it mere genderbased discrimination, or how much does deliberate 'bullying behaviour' mimic signs of superiority, arrogance and entitlement, bordering on psychological personality disorders?" Thorough investigation of the possible role of such behaviour disorders in gender bias and discrimination is long overdue. These disparities and challenges should be actively addressed on all levels by all role players by placing more emphasis on merit, competence and surgical outcomes than on the gender of the surgeon. Despite all these challenges, the benefits of a career in cardiothoracic surgery and tremendous job satisfaction far exceed the disadvantages.
\end{abstract}

Keywords: Cardiothoracic surgery; gender-based discrimination; narcissistic personality disorder; Africa

Submitted Feb 03, 2020. Accepted for publication Oct 27, 2020.

doi: $10.21037 /$ jtd-2020-wts-03

View this article at: http://dx.doi.org/10.21037/jtd-2020-wts-03

\section{Female cardiothoracic surgeons in Africa}

Accurate and up to date data regarding women in cardiothoracic surgery on the African continent is hard to find. With a mere 12 female cardiothoracic surgeons originating from Africa, this article therefore reflects the reality of a very small number of individuals. These small numbers are of great concern and highlights the dire need for more qualified surgeons on the African continent-a need that must be addressed.

Most of the female cardiothoracic surgeons in Africa qualified in South Africa with 10 of a total of 146 cardiothoracic surgeons registered with the Health Professions Council of South Africa (HPCSA) being female. Of those four are working abroad.
The first female cardiothoracic surgeon in South Africa (the author) qualified in 1988 and the first black South African female 20 years later in 2018 (Lindiwe Sidali).

In Africa, as far as it could be ascertained, 2 female cardiothoracic surgeons originated from Nigeria, of whom one is working in the US. Another (Ogadinma Mgbajahwho qualified in 2016) returned to Nigeria with skills in adult and pediatric cardiac surgery. Like most female surgeons she is devoted to creating more opportunities and enabling an environment conducive to training more women to become cardiac and thoracic surgeons (1).

No others could be confirmed in East, Central, North and West Africa, since no central or national formal organization, entity or structure exist where such relevant 
information can easily be sourced (2).

\section{Background and training}

In the USA the first woman to perform open heart surgery was Myra Adele Logan in 1943 (3).

Since then increasing numbers of women across the globe entered and qualified in cardiothoracic surgery (4-8).

The future is expected to introduce even more women to medicine and surgical careers as illustrated by the increases of female surgeons as members of the Colleges of Surgeons over time in many countries, like the UK and Australia (9-11).

In South Africa Cardiothoracic surgical training may commence 3 years post-graduation (MB ChB), and can be completed in no less than another 5 years. During this training, the College requires three formal examinations (primary, intermediate and final) and a logbook of a prescribed minimum number of common required procedures/operations performed as the primary surgeon. This training is often supplemented by fellowships abroad, after completion of their local training.

\section{Cardiac surgery expertise in Africa}

Inequities in the global health workforce are the greatest impediment to health in Africa. Sub-Saharan Africa carries more than $24 \%$ of all the global disease burden but has $3 \%$ of the global health workforce, compared to the Americas who carry only $10 \%$ of the world disease burden but $37 \%$ of the global health workforce (12).

Africa hosts 14\% of World Population and carries 25\% of worldwide Congenital Heart Disease burden.

In 2010, there were a total of 200 cardiologists in South Africa for a population of 52 million (1 per 260,000) and 100 cardiothoracic surgeons ( 1 per 520,000). At the time this figure was nearly 10 times less than in Brazil with its 8,000 board-certified cardiac specialists for a population of 185 million. This translates to 5.7 cardiac specialists per 1 million in South and 43.2 per 1 million in Brazil $(13,14)$.

Sliwa and Zühlke further reported that in South Africa the ratio of physicians per 1,000 population remained static at $0.77 / 1,000$ population from 2004 to 2016 , despite an increase of $34 \%$ in medical students enrolled (more females and African blacks), with only an $18 \%$ increase in the number of graduates for the period 2004 to 2011 (14).

Limitations resulting from inadequate numbers of cardiac care physicians hugely increase the difficulty in meeting escalating service requirements on the African continent.

Centers with cardiac surgery facilities are only found in fewer than half of the countries in Africa. In fact, only two countries-South Africa and Egypt-have independent cardiac surgical programmes, perform more than 500 operations per year and have training facilities for cardiologists and cardiac surgeons. An additional thirteen countries have smaller independent and semiindependent programmes in collaboration with established and well-resourced centers abroad, perform more than 100 operations per year and have some training facilities (15).

\section{Factors contributing to the need for cardiac care in Africa}

Global warming and climate change: This hold tremendous risk for food security with major economic and social implications.

Population growth in Africa: A huge increase in the population of Africa is anticipated during the next century by the United Nations. The population of Nigeria is expected to increase to more than 400 million, while Tanzania's current 53 million will grow to 137 million. Kenya will more than double to 95 million and Uganda from 43 to 106 million over the next 30 years, with the need for cardiac care continuing to grow. The IMF therefore estimates that nearly 20 million high value jobs need to be created only for the number of young people entering the job market. This is not even addressing the enormous existing backlog.

Other contributing factors like poor governance, conflict, poor economic growth, inadequate electrification and climate change are not expected to improve in the short term. Ethiopia may be an exception in this regard (16).

High child mortality rates: The under-five mortality rate continues to improve across the globe with the probability of dying before the age of 5 years estimated at more than 200 per 1,000 live births in at least 11 African countries in 1990, reduced to 5 countries by 2000 and none in 2015 (17).

Burden of heart disease: Simultaneously the burden of heart disease, in particular congenital heart disease, is expected to increase as the birth prevalence remain similar worldwide at $8 / 1,000$ live births.

The need for robust data to support reliable burden of disease calculations for Africa, and the poor survival of affected children may further underestimate the true prevalence of congenital heart disease in Africa $(18,19)$.

Governance in Africa: According to the 2020 Edelman 
Trust Barometer, South Africa was the least trusted government globally. How can this be counted on to improve healthcare? (20).

An article written by Xolisa Philip and published in Daily Maverick on 17 January 2020 came with the heading; "SA stuck in a rut of rot and rhetoric".

The inability to implement promised actions causes great frustration in the society. This is not limited only to South Africa, where conditions overall are better than elsewhere on the continent.

Regrettably the political will to bring about such change is lacking (21).

Furthermore, blatant corruption on the African continent contributed greatly to the lack of cardiothoracic care on the continent.

Evidence presented at The Judicial Commission of Inquiry into Allegations of State Capture, Corruption and Fraud in the Public Sector including Organs of State revealed how millions of dollars were diverted from budgets designed to take care of disadvantaged communities to the pockets of individual politicians and ruthless business enterprises as a result of the reign of corrupt leaders in a patronage system supported by those who directly benefitted and those allowing it, sometimes fearing prosecution (22).

To quote Ella Wheeler Wilcox: "To sin by silence, when they should protest, makes cowards of men."

The recent application to the High Court by Deputy Chief Justice Raymond Zondo to be granted a further extension to the term of the State Capture inquiry—already active for 18 months-is a prime example of the extent and depth of state capture and failure in South Africa (23).

Consequently, many essential services are being provided by many individuals and non-governmental organizations while many other African states too fail in fulfilling their responsibilities.

\section{Gender-based discrimination}

Gender based discrimination is an important contributing factor in the underrepresentation of women in all medical and surgical disciplines, and particularly in cardiothoracic surgery. It is mostly based on subtle, unconscious prejudice and perceptions that individually usually have little harmful intent but can have a disastrous cumulative impact.

A study by Bruce et al. (in 2015 in the USA) demonstrated that $87 \%$ of female medical students, $88 \%$ of residents, and $91 \%$ of practicing surgeons experienced gender-based discrimination in their careers and that this discrimination negatively impacts job satisfaction, perceptions of self-efficacy, relationships between colleagues and career advancement $(24,25)$.

Abelson and others noted that the estimated year when women will represent half of all full professors of surgery has been pushed further into the future from 2,096 to 2,136 $(26,27)$.

These studies in general however reported gender-based discrimination in developed countries only.

The culture of male dominance is strong on the African continent and gender-based violence is rife, but no studies on gender-based discrimination in African countries are available. Such attitudes potentially evolve into intentional harmful behaviour resulting in psychological and even physical harm.

Reports of gender-based violence are common, with rapes and murders of women, young girls and even small children reported daily in our newspapers. Many victims are assaulted in the family and close community.

According to Amnesty International it had reached undeniably alarming levels. Despite many public protests and outcries, only a small number of perpetrators are prosecuted. In 2017, 39,633 rapes and 6,253 sexual assaults were reported in South Africa (28).

\section{Perceptions, prejudice, adversity and challenges}

Female surgeons tend to be successful, most do exceptionally well and manage to overcome adversity. This is most likely due to constant self-criticism, exaggerated dedication and increased scrutiny of females in a maledominated specialty, as they always feel the urge to prove themselves in careers. Indeed, women in general are also not thriving on ego-driven chauvinism.

Several studies indicate more dedicated post-operative care may impact positively on early surgical outcomes. Research by Yusuke Tsugawa at UCLA even suggested that the lowest operative mortality in emergency operations was achieved by female surgeons in their 50's.

Patients, particularly pediatric and critically ill patients, may sense a greater amount of care and compassion, which may constitute a natural advantage experienced by females in medicine. Patient gratitude adds to work satisfaction, but even patients indicate degrees of skepticism and lack of trust towards individuals not fitting a typical stereotype.

In addition, many local female colleagues reported constant exclusion by some male colleagues, with the so- 
called Boys' Club mentality observed throughout the field.

Over many years of training there are such tremendous time constraints and virtually never an opportunity to reflect on personal challenges crossing one's pathway. It is just so much easier to agree to everything and cope with whatever comes your way that the ever-increasing pace of the responsibilities assumed at all levels (in life and work) delays recognizing potentially dangerous undertones in the playing field.

Long training periods, dedication to patients, demanding work schedules and balancing professional and personal priorities pose a real risk of disconnection from family as a situation results where those closest to you become so used to your being absent that their lives continue to your exclusion.

A study by Carnes et al. confirmed such bias and showed that identical work performed by women and men was rated lower in the former once the evaluators knew the work was performed by a woman (29).

These nuances were prominent throughout my own career spanning four decades and most likely played important roles in the background of the experiences reported about Margaret Allen in the USA and Marjan Jahangiri in the UK.

Most of us are hesitant to verbalize this, let alone act on it in the way these women and I had to in order to survive in the field.

This was confirmed by a focus group and interviewbased qualitative study of women in academic surgery that found that, despite the fact that overt discrimination has become increasingly unacceptable in today's world, it still manifests itself in covert forms. It also noted the fact that women often are unwilling to identify as victims. Women want to be respected for their true worth and do not want to feel like any concessions are being made for them. On the other hand, they also may tend to "let things go" in order to avoid coming across as a complainer, which can in itself be harmful professionally. They are torn between wanting to appear strong and being unwilling to put up with the inequities that remain so pervasive (30).

Reporting or acting on these issues also pose a real risk of exacerbating rather than improving the situation.

Were the experiences reported regarding both the Margaret Allen and Marjan Jahangiri gender-based discrimination, or was it more intense? Judge for yourself: around 1985 Margaret Allen founded a heart transplant program at the University of Washington Medical Centre. She is a past president of UNOS. Having trained at UCSD,
King's College London, she then completed her Stanford residency with positive reviews by her chiefs Stuart Jamieson and Norman Shumway.

By 1989, after the appointment of a new chief of surgery, Allen was removed as heart transplant director without explanation, and with a continuous and relentless pattern of animosity, disrespect and discrimination, assisted by a group of critical anesthesiologists. They also attributed increased transplant mortalities during 1996 to her, when she was no longer performing the procedures, citing that she was rather pursuing research interests.

After failing to resolve these false discrimination claims with authorities, a lawsuit followed, where "an incredibly discouraging" settlement was reached around July 2000, though at the cost of her surgical career. She then joined the Hope Heart Matrix Biology Program with Benaroya Research Institute (31).

Marjan Jahangiri, the first female professor of cardiac surgery in Europe, was suspended by colleagues in August 2018.

Iain Quirk, Prof Jahangiri's counsel, said that despite being an extremely skilled surgeon, she had been treated in the "most outrageous" way and was targeted because of "envy at her success" (32).

\section{Personal reflections}

I had the privilege of outstanding training and experienced the evolution of cardiac surgery over more than 35 years under the then Chief of Cardiothoracic Surgery at the Groote Schuur Hospital and the University of Cape Town Medical School Bruno Reichart, followed by further exposure to surgery for congenital heart defects with Marc de Leval in London from 1989-1990. Close collaborative projects with Christiaan Barnard as personal friend, role model and mentor followed until his untimely death in September 2001.

Upon my return from the UK, my duties were deliberately directed away from the interests I have pursued (congenital heart surgery) by subsequent heads of the department. My objections were recorded as insubordination and failure to obey instructions from a superior. Having had no success at convincing the hospital authorities to resolve it, I had to resort to the legal route to have my record cleared.

This discriminatory attitude did not cease and derogatory public references to my abilities continued until those were withdrawn in a settlement that also required traumatic and 
expensive legal action.

In the process I sacrificed a career in academic medicine, and followed a most rewarding career in private practice with well supported opportunities to start new ventures, like surgery for congenital heart defects, cardiac transplantation and extracorporeal circulatory support. The latter was only implemented in the local academic sector more than two decades later.

Independent practice provided for continued medical education, active community service and many other charitable projects over the years.

An increasing workload led to a decision towards succession planning and thus to share the volume of patients with young colleagues. However, this decision regrettably evolved into a relationship of most skilful undermining, divisive and toxic working conditions, which eventually forced me to reach out to the HPCSA. The matter is still ongoing at the time of writing this paper.

Some of these bizarre dynamics I experienced are aptly described in Snakes in Suits by Paul Babiak (PhD), a New York-based industrial and organizational psychologist, who defined different personalities in the workplace as follows: "Most people are honest, loyal, law-abiding citizens who focus their energy on making a living, raising a family, and contributing to society. Others are more selfish, concerned only about themselves, and appear to lack a moral compass."

The book proposed that the victim or target of a bully in the workplace should either leave the service or develop personal strategies to cope. Having had no desirable relocation options, the latter was my only option.

Nowadays far more literature and information are readily available and thus previously experienced observations could be clarified and somehow put into better perspective. It assisted in management of self-doubt and anxiety, precipitated by senseless situations that were way beyond merely individual opinions perpetrated by the "bully".

Better understanding of underlying behaviour patterns had been most helpful and it is crucial for young females entering this wonderful field of medicine to recognize and to develop coping skills against discriminatory behaviour.

Although these toxic attitudes objectively have had little or no effect on my career, such experiences made it much easier to see how unnecessary stumbling blocks and outright rejection and exclusion at times may impact on younger high-achieving females at various stages in training and their early careers, with the direct result being the low number of practising female cardiothoracic surgeons evidenced to date and potentially going forward as well.

\section{Is it perhaps narcissistic personality disorder?}

This viewpoint is included with trepidation though given strength by the Irish philosopher Edmund Burke who said: "All that is necessary for the triumph of evil is that good men do nothing."

Narcissistic personality disorder (NPD) is a natural occurrence in society, occurring in up to $6 \%$ of the general population. It probably has a higher incidence amongst surgeons and even more so in the field of chest surgery.

Recently Leanne Rowe, an Australian physician, referred to the persistent endemic bullying and damaging behaviour in medicine despite many initiatives to improve awareness, mutual respect and a medical culture.

She asked: "Why would doctors do this? And why is it so difficult for others to call them out and intervene effectively?"

Her narrative is most accurate at describing situations and it is impossible to illustrate it better than she did.

The following is a direct quote:

"Fundamentally, a doctor with NPD is arrogant, feels entitled and believes others have a problem. In subtle or not so subtle ways, they let other colleagues know they are 'special', exaggerating their exceptional skills in patient diagnosis and management.

Patients often adore them as they also inflate their achievements in their consulting rooms, while making derogatory comments about the clinical management of other doctors.

Consequently, a doctor with NPD may seem charming on the surface and have many admiring followers. Doctors with NPD may slowly undermine their victims with repetitive nit-picking and sarcasm, drip feed low-grade abuse that is difficult to call out, avoid eye contact, roll their eyes with disdain when no one else is looking or give out backhanded jabs dressed up as jokes.

Others find it difficult to challenge the doctor with NPD as they twist words, misconstrue situations or are easily slighted by routine peer review, constructive feedback or minor criticism.

More severe behaviours of NPD include pathological lying, nasty competitiveness or smear campaigns against other people. This often occurs without the knowledge of victims, who are unable to defend themselves against false rumours because they are the last to find out. The falsehoods often focus on what hurts doctors most, for example, being accused of failing to pull one's weight, a lack of integrity or-worse-incompetence.

To maintain their superior status, power, and control, the perpetrator may also play the martyr or accuse a victim of being toxic, dishonest, mentally unstable or 'not up to it', which causes further barm.

A common myth assumes victims of bullying are oversensitive, weak individuals who are unable to stand up for themselves. More 
often, bullies target bigh achieving victims who they envy. When a target lacks boundaries in relation to self-protection and selfcare, they try to appease and tolerate the bully for too long. The mind games are irrational, and there is nothing the victim can do to fix the situation when the rules keep changing. Any individual intervention only makes matters worse.

In response, victims naturally become upset, byper-vigilant and defensive, and when their stressed demeanour confirms the doubts of colleagues about their mental bealth, they may gradually lose their support network.

Recommending self-care strategies, resilience training and cognitive behavioural techniques in this situation can be harmful because further responsibility is placed on the shoulders of the victim to change, but this doesn't stop the bully's destructive behaviour" (33).

I have observed how otherwise kind-hearted colleagues, who did not display NPD-characteristics, silently observed the abusive approaches of NPD-colleagues. They do not speak out against the NPD-doctors, maybe fearing to become the secondary target of the bullying.

The Mayo Foundation defined signs and symptoms of narcissistic personality disorder. The severity of symptoms may vary. Such people can:

* Have an exaggerated sense of self-importance;

* Have a sense of entitlement and require constant, excessive admiration;

* Expect to be recognized as superior even without achievements that warrant it;

* Exaggerate achievements and talents;

* Be preoccupied with fantasies about success, power, brilliance, beauty or the perfect mate;

* Believe they are superior and can only associate with equally special people;

* Monopolize conversations and belittle or look down on people they perceive as inferior;

* Expect special favours and unquestioning compliance with their expectations;

* Take advantage of others to get what they want;

* Have an inability or unwillingness to recognize the needs and feelings of others;

* Be envious of others and believe others envy them;

* Behave in an arrogant or haughty manner, coming across as conceited, boastful and pretentious;

* Insist on having the best of everything.

At the same time, people with narcissistic personality disorder have trouble handling anything they perceive as criticism, and they can:

* Become impatient or angry when they don't receive special treatment;

* Have significant interpersonal problems and easily feel slighted;

* React with rage or contempt and try to belittle the other person to make themselves appear superior;

* Have difficulty regulating emotions and behaviour;

* Experience major problems dealing with stress and adapting to change;

* Feel depressed and moody because they fall short of perfection;

* Have secret feelings of insecurity, shame, vulnerability and humiliation (34).

\section{Conclusions}

Huge inequalities and challenges exist on the African continent in terms of the current status quo, compounded by ineffectual, inadequate action to address the shortages of medical practitioners in general and female surgeons involved with cardiac care in particular.

This is exacerbated by the slow equalization of females compared to males in cardiothoracic surgery, which is out of keeping with natural gender bias.

Whilst it is acknowledged that behavioural disorders do not discriminate based on gender, profession or geography, NPD may be more prevalent, but not restricted to male cardiothoracic surgeons.

Intentional counter-productive attitudes by some colleagues may be regarded as more intense and deliberately harmful gender-based discrimination that may actually display inherent aspects of narcissistic personality disorder.

It is noted with concern that a surgeon with NPD has the potential to impact negatively on patient care, not only by discouraging skilled female surgeons, but also by driving clinical management based on ego and not at all times in the best interest of the patient.

These disparities and challenges should be actively addressed on all levels by all role players by placing more emphasis on merit, competence and surgical outcomes than on the gender of the surgeon.

Despite these challenges, the benefits of a career in cardiothoracic surgery and tremendous job satisfaction far outweigh the disadvantages.

\section{Acknowledgments}

Funding: None. 


\section{Footnote}

Provenance and Peer Review: This article was commissioned by the Guest Editors (Cecilia Pompili and Leah Backhus) for the series "Women in Thoracic Surgery" published in Journal of Thoracic Disease. The article has undergone external peer review.

Conflicts of Interest: The author has completed the ICMJE uniform disclosure form, available at: http://dx.doi. org/10.21037/jtd-2020-wts-03. The series "Women in Thoracic Surgery" was commissioned by the editorial office without any funding or sponsorship. The author has no other conflicts of interest to declare.

Etbical Statement: The author is accountable for all aspects of the work in ensuring that questions related to the accuracy or integrity of any part of the work are appropriately investigated and resolved.

Open Access Statement: This is an Open Access article distributed in accordance with the Creative Commons Attribution-NonCommercial-NoDerivs 4.0 International License (CC BY-NC-ND 4.0), which permits the noncommercial replication and distribution of the article with the strict proviso that no changes or edits are made and the original work is properly cited (including links to both the formal publication through the relevant DOI and the license). See: https://creativecommons.org/licenses/by-nc-nd/4.0/.

\section{References}

1. Featured Profile and Interview With Ogadinma Mgbajah, MBBS. Available online: https://www.ctsnet.org/article/ featured-profile-and-interview-ogadinma-mgbajah-mbbs, Nov 8, 2017.

2. Web searches, Communications with individual colleagues and Prof Charles Yankah of PASCaTS (Pan-African Society for Cardiothoracic Surgery).

3. Myra Adele Logan. Available online: https://en.wikipedia. org/wiki/Myra_Adele_Logan

4. Available online: https://www.nlm.nih.gov/exhibition/ aframsurgeons/morenotable.html

5. Magliato K. TIME magazine, April 8, 2016. Available online: https://time.com/4282724/success-adviceheartbeat-kathy-magliato/

6. Shemin RJ, Ikonomidis JS. Thoracic Surgery Workforce: report of STS/AATS Thoracic Surgery Practice and
Access Task Force--Snapshot 2010. Ann Thorac Surg 2012;93:348-55, 355.e1-6.

7. Data from the Accreditation Council for Graduate Medical Education Data Resource Book. Available online: https:// www.acgme.org/About-Us/Publications-and-Resources/ Graduate-Medical-Education-Data-Resource-Book

8. Capdeville M. Gender Disparities in Cardiovascular Fellowship Training Among 3 Specialties From 2007 to 2017. J Cardiothorac Vasc Anesth 2019;33:604-20.

9. NHS 7 June 2018 - Surgeons by gender, specialty and grade, 31 Jan 2018. Available online: https://digital.nhs. uk/data-and-information/find-data-and-publications/ supplementary-information/2018-supplementaryinformation-files/staff-numbers/consultants-and-doctors/ surgeons-by-gender---speciality-and-grade

10. Women in Surgery. Available online: https://www.rcseng. ac.uk/careers-in-surgery/women-in-surgery

11. Seebacher N. Gender Equity in Medical Specialities. Available online: https://www.amsa.org.au/sites/amsa.org. au/files/Gender\%20Equity\%20in\%20Leadership\%20 and $\% 20$ the $\% 20$ Workforce $\% 20 \% 282017 \% 29$.pdf

12. Anyangwe SC, Mtonga C. Inequities in the global health workforce: the greatest impediment to health in sub-Saharan Africa. Int J Environ Res Public Health 2007;4:93-100.

13. Taylor J. Cardiology in Brazil: a country in development. Eur Heart J 2010;31:1541-2.

14. Sliwa K, Zuhlke L, et al. Cardiology-cardiothoracic subspecialty training in South Africa: a position paper of the South African Heart Association. Cardiovasc J Afr. 2016;27:188-93.

15. Zühlke L, Mirabel M, Marijon E. Congenital heart disease and rheumatic heart disease in Africa: recent advances and current priorities. Heart 2013;99:1554-61.

16. Available online: https://www.dailymaverick.co.za/ article/2020-01-20-move-quickly-or-be-damned-theimperative-of-african-competitiveness

17. UNICEF, WHO, World Bank, UN DESA/Population Division Levels and Trends in Child Mortality 2015, UNICEF 2015. Available online: https://data.unicef.org/ resources/levels-and-trends-in-child-mortality-2015/

18. Mocumbi AO, Lameira E, Yaksh A, et al. Challenges on the management of congenital heart disease in developing countries. Int J Cardiol 2011;148:285-8.

19. Mocumbi AO. The challenges of cardiac surgery for African children. Cardiovasc J Afr 2012;23:165-7.

20. Available online: https://www.edelman.com/ trustbarometer

21. Available online: https://subscriptions.touchbasepro.com/ 
t/d-1-xudulhl-wyddtykhj-x/

22. The Judicial Commission of Inquiry into Allegations of State Capture, Corruption and Fraud in the Public Sector including Organs of State. Available online: https:// sastatecapture.org.za/

23. Zondo gives update on inquiry's extension request. Available online: https://ewn.co.za/2020/01/23/watch-livezondo-gives-update-on-inquiry-extension-request

24. Bruce AN, Battista A, Plankey MW, et al. Perceptions of gender-based discrimination during surgical training and practice. Med Educ Online 2015;20:25923.

25. Barnes KL, McGuire L, Dunivan G, et al. Gender Bias Experiences of Female Surgical Trainees. J Surg Educ 2019;76:e1-e14.

26. Abelson JS, Chartrand G, Moo TA, et al. The climb to break the glass ceiling in surgery: trends in women progressing from medical school to surgical training and academic leadership from 1994 to 2015. Am J Surg 2016;212:566-572.e1.

27. Sexton KW, Hocking KM, Wise E, et al. Women in academic surgery: the pipeline is busted. J Surg Educ 2012;69:84-90.

28. Available online: https://www.iol.co.za/news/politics/

Cite this article as: Vosloo SM. Realities and challenges for female cardiothoracic surgeons: an African perspective. J Thorac Dis 2021;13(1):448-455. doi: 10.21037/jtd-2020-wts-03 amnesty-international-decries-alarming-levels-of-genderbased-violence-in-sa-32066522

29. Carnes M, Bartels CM, Kaatz A, et al. Why is John More Likely to Become Department Chair Than Jennifer? Trans Am Clin Climatol Assoc 2015;126:197-214.

30. Webster F, Rice K, Christian J, et al. The erasure of gender in academic surgery: a qualitative study. Am J Surg 2016;212:559-65.

31. Transplant News. July 14, 2000. Available online: https:/www.ncbi.nlm.nih.gov/pmc/articles/ PMC2586600/?source=post_page-

32. Feuding surgeons put patients at risk at heart surgery unit, report finds. Available online: https://www.telegraph. co.uk/news/2018/08/04/feuding-surgeons-put-patientsrisk-heart-surgery-unit-report/

33. Rowe L. How to spot a narcissistic doctor. May 3, 2018. Available online: https://www.kevinmd.com/blog/2019/05/ how-to-spot-a-narcissistic-doctor.html

34. From: 1998-2020 Mayo Foundation for Medical Education and Research (MFMER). Available online: https:// www.mayoclinic.org/diseases-conditions/narcissisticpersonality-disorder/symptoms-causes/syc-20366662 